\section{Postviral fatigue syndrome}

This is a syndrome that may or may not follow what appears to be an acute infectious illness, and may occur in epidemic or sporadic forms consisting of persisting or relapsing 'fatigue' or easy fatiguability of at least six months' duration, for which no other cause is apparent. It is associated with a number of other variable features including mild fever, sore throat, painful lymph nodes, headaches, muscle pain, migratory arthralgia, photophobia, forgetfulness, irritability, concentration difficulties, depression, and sleep disturbance. It has been recognised since the early 1930s and known by a wide variety of names including Iceland disease, Royal Free disease, epidemic neuromyasthenia, myalgic encephalomyelitis, postviral syndrome, and more recently chronic fatigue syndrome. ${ }^{1}$

Although predominantly a disorder of young adults, it has been recognised in children with either an acute or insidious onset. At least $10-15$ cases of the sporadic form are seen each year at the Hospital for Sick Children, Great Ormond Street, with lethargy, headache, abdominal pain, and subjective muscular weakness being the most common manifestations. Abnormal physical findings are usually conspicuous by their absence but occasionally pharyngeal injection, tender cervical lymph nodes, and muscle tenderness are present. A proportion of patients have an 'atypical' lymphocytosis, increased plasma creatine phosphokinase activity, circulating immune complexes, minor changes on electroencephalography and electromyelography, increased serum Epstein-Barr and Coxsackie B antibody titres, and VPI antigen in serum. Some workers have demonstrated enteroviral RNA in muscle biopsy material. ${ }^{2}$ Although an infective aetiology has been invoked, however, the full nature of the illness remains obscure and is probably a mixture of an initial infective insult followed by or associated with an important psychological component.

The continuing debate as to whether myalgic encephalomyelitis or postviral syndrome is predominantly organic or psychological is unhelpful. ${ }^{34}$ As with most childhood illness, it is more useful to pay due consideration to all possible contributory factors including biological, social, and psychological. ${ }^{5}$ Elements that have been noted to contribute to the latter include depression, anxiety, school phobia, and family factors such as parental overprotectiveness and over involvement, marital tensions affecting the child, and determination to perceive the problem as exclusively biological.

The polarisation of views concerning the nature of the condition has inevitably affected the approach to management. A number of approaches previously advocated including rest, vitamins, dietary exclusions, immunoglobulin injections, plasmapheresis, and antiviral agents have not clearly been consistently beneficial. ${ }^{3}$ At Great Ormond Street, a programme consisting of optimism, support, and rehabilitative strategies is the mainstay of management. Analgesics are used as required. Graded remobilisation is commenced as early as possible. Too rapid mobilisation is likely to lead to early relapse, while continued complete rest can induce a vicious cycle of immobility and, ${ }^{6}$ in more severe cases, contractures. The child is encouraged to start with as little as $\mathbf{3 0}$ minutes of activity daily divided into two periods, gradually increasing amounts every few days. School return should also be initiated gradually, but definitely, in the same manner. Rarely are antidepressants indicated or of value, but where feelings of guilt, worthlessness, and suicidal ideation are superimposed upon loss of appetite, sleep disturbance, impaired concentration, and psychomotor retardation, then a course of a tricyclic such as amitriptyline $50-100 \mathrm{mg}$ at night for six weeks can be tried as a complement to other treatments.

Family factors that appear to be contributing to maintenance of a disorder should also be tackled. Clearly parental cooperation is required in any remobilisation programme however gradual. When parents express dismay or disagreement, it is helpful to explore their concerns and to explain clearly the rationale, allowing ample time for questions and discussion. Parental support and counselling is necessary throughout the treatment, and family therapy is indicated when there are obvious family problems. The prognosis is variable and most recover completely once the treatment programme is initiated. Only a few children remain, or become, chronic invalids and usually they have parents who are unable or unwilling to accept a comprehensive approach to treatment.

Finally, care should be taken by the profession to avoid unnecessarily burdening children and their parents with a diagnosis of myalgic encephalomyelitis or postviral syndrome. Harris and Taitz have noted that the proffered diagnosis has frequently lead to extensive, unnecessary investigation and inappropriate and untested treatment. ${ }^{7}$

B LASK

The Hospital for Sick Children, M J DILLON

Great Ormond Street,

London WCIN $3 f H$

1 Dillon M. Epidemic neuromyesthenia at the Hospital for Sick Children, Great Ormond Street, London. Postgrad Med $\mathcal{J}$ 1978;54:725-30.

2 Yousef G, Bell E, Mann G, et al. Chronic enterovirus infection in patients with post-viral fatigue syndrome. Lancet 1988;i:146-50.

3 David A, Wessely S, Pelosi A. Post viral fatigue syndrome: time for a new approach. Br Med $\mathcal{F}$ 1988;296:696-8.

4 Thomas P. Post-viral fatigue syndrome. Lancet 1987;i:218.

5 Lask B, Fosson A. Childhood illness - the psychosomatic approach. Chichester: John Wiley, 1989.

6 Shepherd C. Post-viral fatigue syndrome. Br $\mathcal{F}$ Hosp Med 1989;2:250.

7 Harris F. Taitz L. Damaging diagnoses of myalgic encephalitis in children. $\mathrm{Br}$ Med $\mathcal{f}$ 1989;299:790. 